\title{
Effect degree of temperature subcooling in the performance of refrigeration with CFC, HFC and hydrocarbons refrigerant
}

\author{
Prayudi Suparmin ${ }^{1, *}$, Vendy Antono ${ }^{1}$, and Roswati Nurhasanah ${ }^{1}$ \\ ${ }^{1}$ College of Engineering Technology PLN, Mechanical Engineering Department, 11750 Jakarta, Indonesia
}

\begin{abstract}
Global warming is the result of the use of Chloro Fluoro Carbon (CFC) and Hydro Flouro Carbon (HFC) refrigerants. CFC and HFC refrigerants are not environmentally friendly in air conditioning systems. Researchers conducting the research to find an alternative refrigerant with hydrocarbon and the use of liquid suction heat exchanger (LSHX) subcooling in the vapor compression refrigeration system. One kind of LSHX is heat exchanger between tube to tube. Retrofit refrigerant is used to find a replacement refrigerant for R22, R134a, R404A with R600, and mixture refrigerant R290/R600a in the ratio 50:50. From the analysis are conclude that the increases of degree of subcooling temperature significantly affects to the effectiveness of LSHX, increase the refrigeration capacity and also refrigeration capacity index, increase the compressor of work, compressor work of index, COP and COP index. The parameters of the indicators that mixture the refrigerant R290/R600a in the ratio of 50:50 can be used as a substitution for R404A and R22, while the R600 refrigerant can be used as a substitution for R134a in the vapor compression refrigeration system with LSHX.
\end{abstract}

\section{Introduction}

In advanced, technology of air conditioning or refrigeration system is influence on human life. There are three major issues associated with the vapor refrigeration system to save energy, ozone layer depletion and also global warming that caused by the use of refrigerant which is not environmentally friendly. Refrigeration or air conditioning systems is generally use electricity. Based on the several studies shows that electricity which is used for refrigeration systems in the building were highest $50 \%$. In the cold storage system and supermarket require energy consumption 50\%-60\% [1]. Energy power consumption as used to get a big difference temperature between output temperature of the condenser and input of the evaporator, implications increase compressor work in requires the amount of energy that fairly large [2]. One method that can be increase refrigeration capacity is use LSHX subcooling.

Performance refrigeration system with LSHX and using the refrigerant R22, R404A, R134a, R1234ze, and R1234yf influenced by the degree of subcooling in the condenser. Optimum Performance is when using R1234yl. Degree of temperature subcooling maximum depends on the condensation temperature [3].The value of degree of temperature subcooling on vapor compression refrigeration system with LSHX optimal between $2-6^{\circ} \mathrm{C}$. Optimal degree of temperature subcooling is strongly influenced by temperature condensation, but it is not temperature evaporation. Low cooling water temperature in the condenser improves performance, heat transfer, and energy destruction [4].
The research for hydrocarbon refrigerant R290, $\mathrm{R} 600, \mathrm{R} 600 \mathrm{a}$ as alternative R134a in vapor compression refrigeration system with subcooling resulted obtain R600 and R600a has the same characteristics as R134a, the saturation pressure is greater than R134a and R290.Performance R600 and R600a in the subcooling refrigeration system better than the R290 and R134a [5]. Incorporation of subcooling heat exchanger in the system, greatly improved the performance of the system, its increases the COP, reduces the input of compressor energy and the specific power consumption of the system. The thermodynamic properties of R432A and $\mathrm{R} 433 \mathrm{~A}$ are match with $\mathrm{R} 22$ and the two refrigerants consistently exhibited better performance than R22 in sub-cooling heat exchanger refrigeration system. Performing of R433A is better than both of R22 and $\mathrm{R} 432 \mathrm{~A}$ in that the highest RCI, COP, reduction in energy input, and lowest discharge temperature were obtained using R433A in the system [6-7].

Based on the research with three mixture refrigerant hydrocarbon Propane (R290), Butane (R600) and Isobutene (R600a) with the comparison [70:25:5] and [50:40:10] have similar characteristics thermodynamic to $\mathrm{R} 134 \mathrm{a}$. The similarly is a mixture of two refrigerant R290/R600 and R290/R600a with the composition [60.40] have saturated temperature and saturated pressure of each refrigerant this indicates that neither mixture matches closely with HFC-134a. In this case, both of the mixtures may be selected as suitable alternatives [13].

In general, the degree of temperature subcooling is impact on the performance refrigeration system and the

* Corresponding author: prayudi@sttpln.ac.id 
majority of research for a replacement refrigerant R22, R134a with hydrocarbons. In this paper, the thermodynamic analysis of vapor compression refrigeration system with LSHX are used working fluid refrigerant type of $\mathrm{CFC}, \mathrm{HFC}$ and hydrocarbons, while the type of refrigerant are used R22, R134a, R404A, R600 and mixture with refrigerant R290/R600a. The main objective of this paper is to present whether refrigeration R600 and R290/R600a can be used as a substitute refrigerant R22, R134a and R404A in the vapor compression refrigeration system with LSHX.

Cycle vapor compression refrigeration system with subcooling is given in Fig. 1. According to Klein[9], Liquid-suction heat exchangers are commonly installed in refrigeration systems with the intent of ensuring proper system operation and increasing system performance. Specifically, ASHRAE (1998) states that liquid-suction heat exchangers are effective in (1) increasing the system performance; (2) subcooling liquid refrigerant to prevent flash gas formation at inlets to expansion devices; (3) fully evaporating any residual liquid that may remain in the liquid-suction prior to reaching the compressor(s). LSHX is a heat exchanger which is added between the condenser and evaporator in air conditioner. With the aids of LSHX, the refrigerant came out from condenser is further cooled down by the refrigerant from the outlet of evaporator.

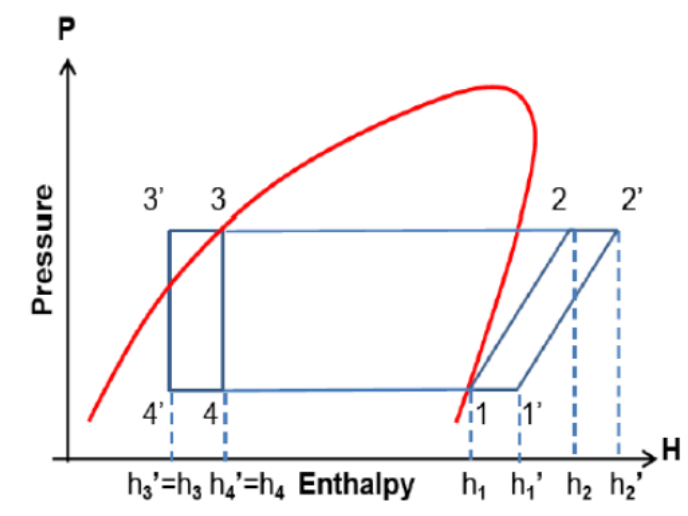

Fig.1. P-H Diagram refrigeration system with subcooling

From Fig. 1, the cycle of vapor compression refrigeration system without subcooling is $1-2-3-4$, while LSHX subcooling is $11^{\prime}-22^{\prime}-3^{\prime}-4$ '. The degree of freedom temperature of subcooling $\left(\Delta \mathrm{T}_{\text {sub }}\right)$ is the difference between the temperature of saturation with subcooling fluid temperature before it enters the expansion valve is the difference between $\mathrm{T}_{3}-\mathrm{T}_{3}$,

$$
\Delta T_{\text {sub }}=T_{3}-T_{3^{\prime}}
$$

Meanwhile, heat transfer on LSHX can be described by the Fig. 2.

The effectiveness on LSHX given by equation $[9,11]$

$$
\varepsilon_{\mathrm{LSHX}}=\frac{T_{1^{\prime}}-T_{1}}{T_{3}-T_{1}}
$$

Performance vapor compression refrigeration system with LSHX, influence the degree of temperature subcooling can be reviewed the effect on the refrigeration capacity index (RCI), the compressor work index $(\mathrm{WI})$, and the index of the $\mathrm{COP}\left(\mathrm{COP}_{\mathrm{N}}\right)$ is given by equation $[5,12]$,

$$
\begin{aligned}
\mathrm{RCI} & =\frac{\mathrm{RC}_{\text {LSHX }}}{\mathrm{RC}_{\text {no-LSHX }}} \\
\mathrm{WI} & =\frac{\mathrm{W}_{\text {LSHX }}}{\mathrm{W}_{\text {no-LSHX }}} \\
\mathrm{COP}_{\mathrm{N}} & =\frac{\mathrm{COP}_{\text {LSHX }}}{\mathrm{COP}_{\text {no-LSHX }}}
\end{aligned}
$$

where $\mathrm{RC}_{\mathrm{LSHX}}, \mathrm{W}_{\mathrm{LSHX}}$ and $\mathrm{COP}_{\mathrm{LSHX}}$ can be seen in the paper [5], and [12].

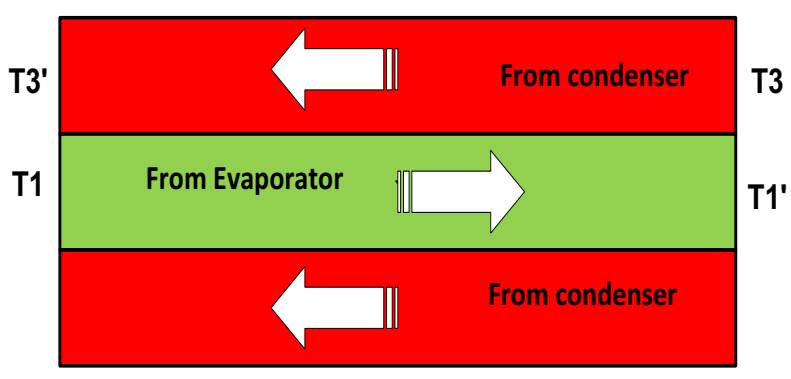

Fig.2. Schematic diagram of heat transfer

\section{Experimental setup}

Test equipment used is RTU Cold Storage Mini with LSHX tube and tube (Fig. 3), with the cooler box shown in Fig. 4.

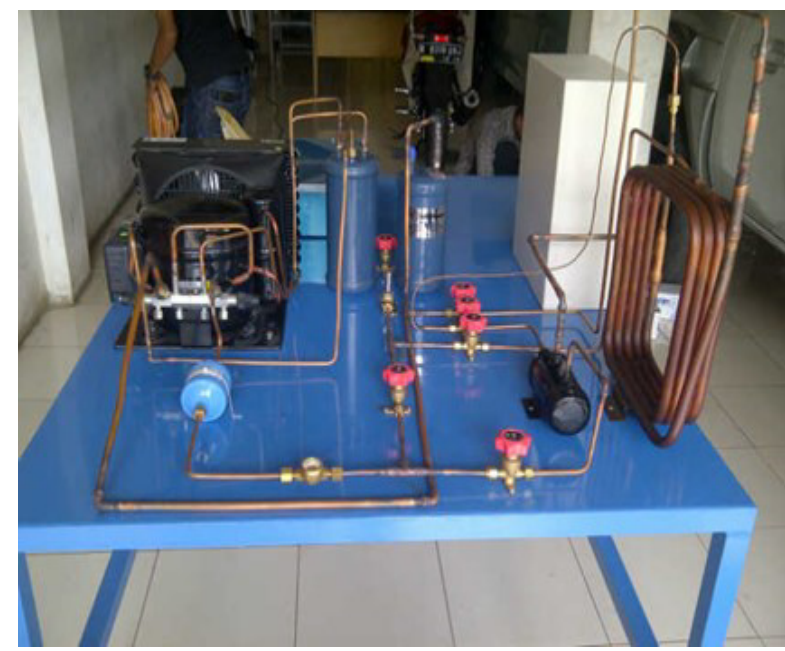

Fig. 3. Test equipment RTU cold storage

The system also equipped with measuring devices, accessories and other auxiliary equipment such as pressure gauge, digital thermocouple, oil separator, separator (for refrigerant), shut off valve, sight glass and filter dryer. Number of thermocouples mounted as many as six pieces, and two pieces of a pressure gauge suction and discharge compressor. Refrigerant used CHC type is $\mathrm{R} 22$, HFC type is R134a, R404A and hydrocarbon type refrigerant R600 and mixture refrigerant R290/R600a with the ratio 50:50. 


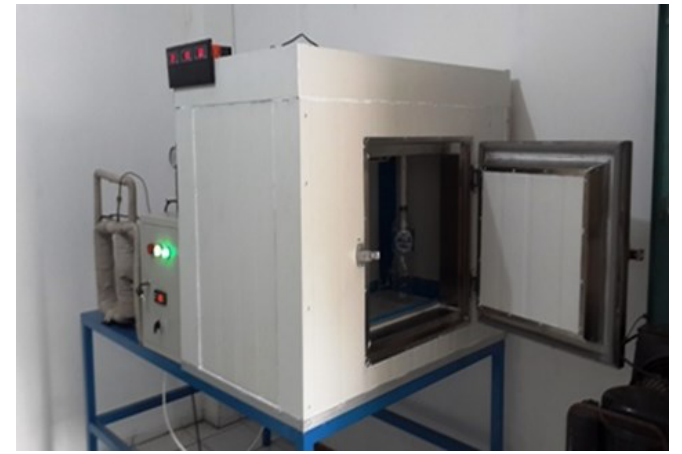

Fig. 4. Box cooling cold storage

The refrigerant is compressed by the compressor hermetic, Tecumseh CAJ9480T power input 0.5 HP, maximum compression pressure of 50 bar. Retrieval of data starting from 0 minutes up to 60 minutes, looking from the degree of temperature subcooling until $7^{\circ} \mathrm{C}$ according to the results research [5]. The calculation of the value of the enthalpy base on pressure and temperature used software Cooldpack Ver 1.50.

\section{Result and discussion}

\subsection{Effect degree of temperature subcooling on the effectiveness LSHX}

Using the lowest temperature of LSHX, in the RTU cold storage with R22 is $-14.6^{\circ} \mathrm{C}, \mathrm{R} 134 \mathrm{a}$ is $-9.4^{\circ} \mathrm{C}, \mathrm{R} 404 \mathrm{~A}$ is $24.4^{\circ} \mathrm{C}, \mathrm{R} 600$ is $-5.9^{\circ} \mathrm{C}$, and mixture R290/R600a is $21.6^{\circ} \mathrm{C}$. From the temperature in the RTU cold storage, the mixture refrigerant $\mathrm{R} 2690 / 600 \mathrm{a}$ has been similar characteristics to R404A. The relationship between the degree of temperature subcooling to the effectiveness LSHX is given in Fig. 5.

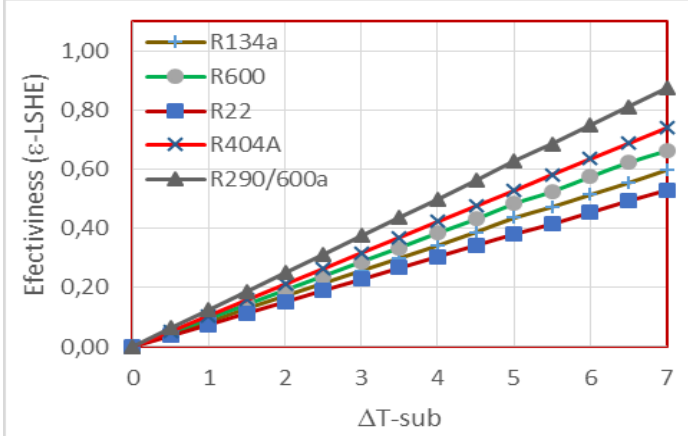

Fig. 5. Effect $\Delta$ Tsub to effectiveness LSHX

From Fig. 5, its show that if the degree of subcooling temperature increases, the effectiveness LSHX also increased. Lowest effectiveness LSHX with using refrigerant R22 and the highest using mixture refrigerant R290/R600a, $\varepsilon=0.88$. Average effectiveness LSHX for R22, R134a, R404A, R600 and R290/R600a respectively $0.267,0.301,0.370,0.335$, and 0.438 . From Fig. 5, the effectiveness of LSHX with a mixture of refrigerant R290/R600a approached characteristics R404A, and effectiveness refrigerant R600 approached characteristics R134a.

\subsection{Effect of degree of temperature subcooling to increase the refrigeration capacity.}

By using LSHX subcooling, the average of refrigeration capacity for R22, R134a, R404A, R600 and mixed refrigerant R290/R600a respectively are $160.07 \mathrm{~kJ} / \mathrm{kg}$, $149.69 \mathrm{~kJ} / \mathrm{kg}, 123.01 \mathrm{~kJ} / \mathrm{kg}, 271.93 \mathrm{~kJ} / \mathrm{kg}$ and 282.56 $\mathrm{kJ} / \mathrm{kg}$. LSHX subcooling lead to increase refrigeration capacity and refrigeration capacity index given by Fig. 6 and Fig. 7. The Fig. show that if the degree of temperature subcooling increase, the refrigeration capacity also increase

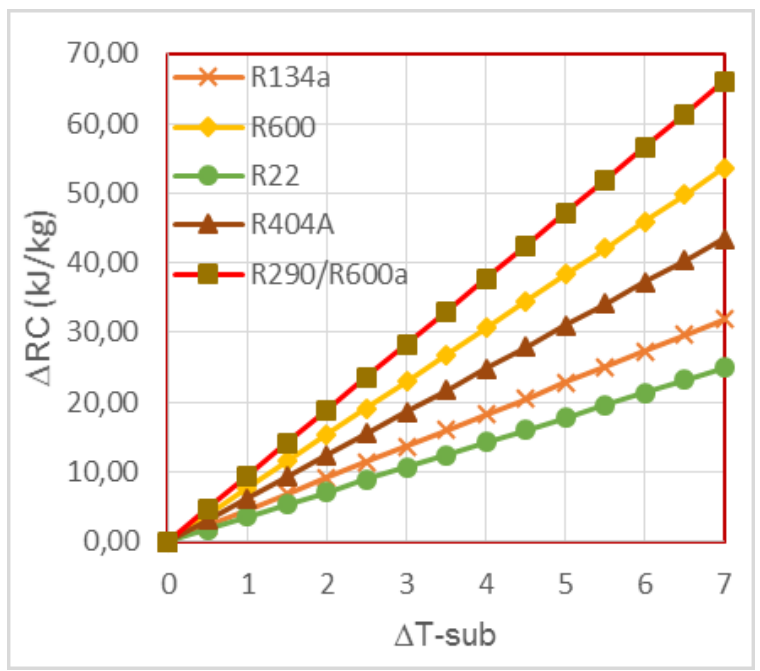

Fig.6. Effect $\Delta \mathrm{T}$ sub to $\Delta \mathrm{RC}$

Fig. 6, its shows that the increase in refrigeration capacity with a mixture refrigerant R290/R600a is greater compared with the others, while the lowest increase refrigeration capacity using refrigerant R22. The average increase in refrigeration capacity than without LSHX for R22, R134a, R404A, R600 and mixture refrigerant $\mathrm{R} 290 / \mathrm{R} 600 \mathrm{a}$ respectively is 12.46 $\mathrm{kJ} / \mathrm{kg}, 15.95 \mathrm{~kJ} / \mathrm{kg}, 21.72 \mathrm{~kJ} / \mathrm{kg}, 26.81 \mathrm{~kJ} / \mathrm{kg}$, and 33.01 $\mathrm{kJ} / \mathrm{kg}$. From indicators the increased refrigeration capacity, the use mixed refrigerant R290/R600a has characteristics similar to R600, and refrigerant R600 has characteristics similar to R404A.

Fig.7 shows the effect the degree of temperature subcooling to the refrigeration capacity index. The Fig.s show that if the degree of temperature subcooling increases, also refrigeration capacity index increased. Usage LSHX and mixture refrigerant R290/R600a has an refrigeration capacity index most large compared with the other, while using refrigerant R22 has the lowest refrigeration capacity index. The average increase in refrigeration capacity index for R22, R134a, R404A, R600 and mixture R290/R600a respectively are 1.09, $1.12,1.08,1.11$ and 1.13 . This means that the average increase largest in refrigeration capacity is used mixture R290/R600a, where percentage in increase refrigeration capacity is $13 \%$. 


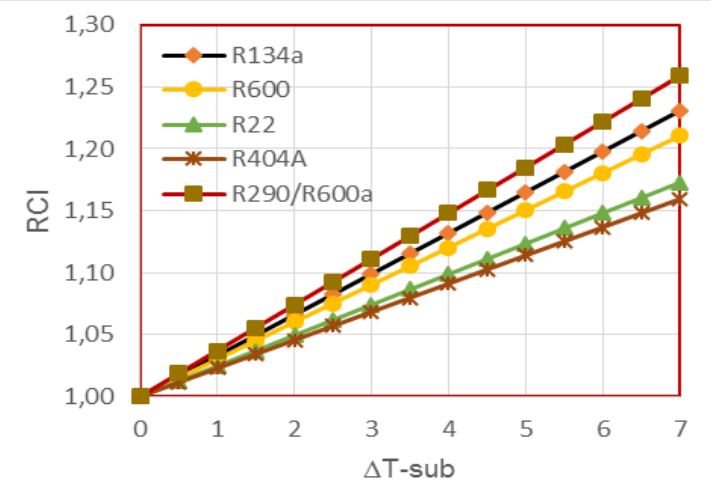

Fig.7. Effect $\Delta$ Tsub to RCI

With the indicators increase refrigeration capacity (Fig.6), refrigeration capacity index (Fig.7) which function of the degree of temperature subcooling, that mixture refrigerant R290/R600a has a characteristic similar to R134a, and R600 has characteristic similar to R404A. So that the mixture refrigerant R290/R600a can be used as a substitute for R600 and R404A, and R600 can be used as a substitute for R404A in the vapor compression refrigeration system with LSHX. This result relevant to the research [8] and [10].

\subsection{Effect degree of temperature subcooling to work compressor.}

To see the impact of the installation LSHX subcooling to work may be viewed from the compression ratio between the discharge and suction pressure, increase in work compressor, and work compressor index.

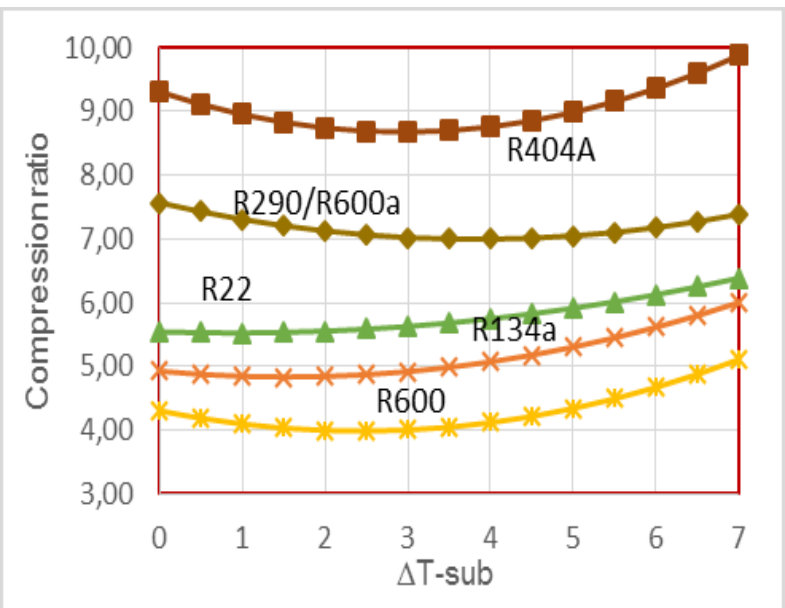

Fig.8. Effect $\Delta \mathrm{Tsub}$ to compression ratio

Fig. 8 shows that the increase pressure ratio work compresso, where the compression work ratio is between 4 to 9 and the minimum value of the compression ratio is at condition degree of temperature subcooling between 3-5 degrees. The average compression ratio for R22, R134a, R404A, R600 and R290/R600a respectively is 5.99, 5.17, 9.04, 4.30 and 7.18. The highest compression ratio using refrigerant $\mathrm{R} 404 \mathrm{~A}$, and the lowest use of refrigerant R600. The magnitude of this compression ratio shows the amount of work the compressor performed by the system, which can be seen from the increase in compressor work if the degree of temperature subcooling rise. From indicators work compressor, characteristics mixture refrigerant R290/R600a similar to R404A and, characteristics refrigerant R600 similar to R134a. These results are relevant to papers [13].

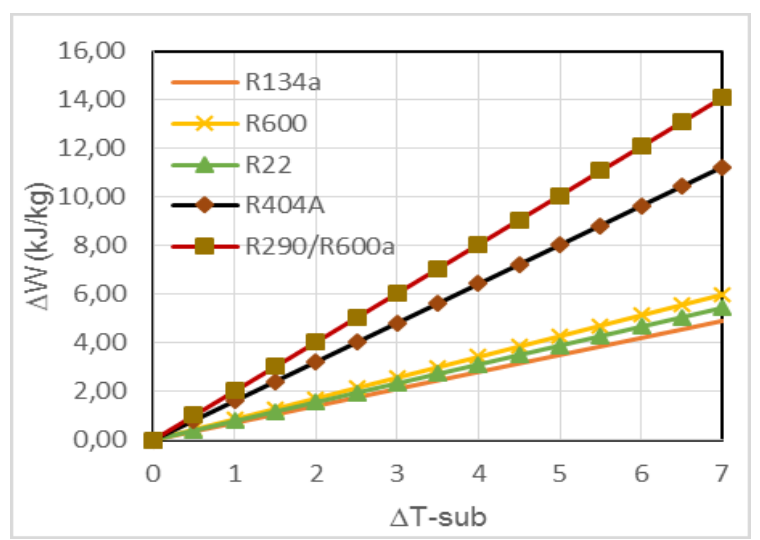

Fig.9. Effect $\Delta \mathrm{Tsub}$ to increase work compression

The Fig.9 as show that if the degree of temperature of subcooling increase, the work compressor work also increased in vapor compression refrigeration system with LSHX subcooling. The average of increasing in work of compressor that use LSHX subcooling for R22, R134a, R404A, R600 and R290/R600a respectively $2.72 \mathrm{~kJ} /$ $\mathrm{kg}, 2.45 \mathrm{~kJ} / \mathrm{kg}, 5.62 \mathrm{~kJ} / \mathrm{kg}, 2.99 \mathrm{~kJ} / \mathrm{kg}$ and $7.04 \mathrm{~kJ} / \mathrm{kg}$. Mixture refrigerant R290/R600a has the largest increase in compressor work. Evaluating from the increase work of compressor, characteristic mixture refrigerant R290/R600a close to characteristics R404A, and characteristic R600 close to R22. These results are relevant to reported of the paper [3], [6] and [9].

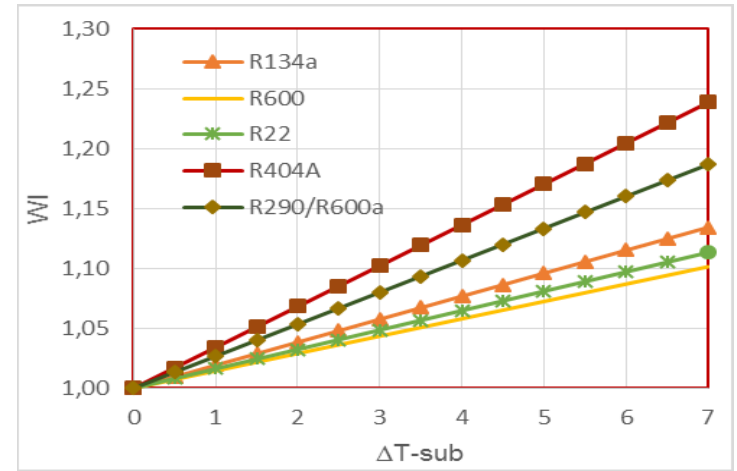

Fig.10. Effect $\Delta$ Tsub to work compressor index

The work compressor index shows that a rise work compressor as a percentage, which is shows in Fig.10. The average of work compressors index for R22, R134a, R404A, R600 and R290/R600a respectively are 1.06, 1.07, 1.12, 1.05 and 1:09. From Fig. 10, when degrees temperature subcooling increases, the work compressor index also increased. This shows that used LSHX would result in the ratio and the work compressor increasing. The largest work compressor index if used refrigerant R404A and the lowest work compressor index with R600. Meanwhile, are work compressor index R290/ R600a still under R404A and above R134a. 
Based on the relationship between the degree of temperature subcooling with a working compressor, work compressor index that mixture refrigerant R290/R600a has close characteristics to R134a and R404A, and characteristics R600 close to R22, so that the refrigerant mixture R290/R600a can be used as substitute for R134a, while the R600 can be used as substitute R22 in vapor compression refrigeration system with LSHX

\subsection{Effect degree of temperature subcooling to COP}

The average value $\mathrm{COP}_{\mathrm{LSHX}}$ for refrigerant R22, R134a, R404A, R600 and R290/R600a respectively are 3.31, 4.22, 2.47, 3.59 and 4.85. The Fig. 11 show that the value optimum COP $\mathrm{LSHX}_{\text {as }}$ function of the degree of temperature subcooling between $3-5^{\circ} \mathrm{C}$.. This result relevant to research [4]. $\mathrm{COP}_{\text {LSHX }}$ are greatest using $\mathrm{R} 600$, and the lowest use of R404A. This result is relevant that refrigerant $\mathrm{R} 404 \mathrm{~A}$ has largest compression ratio, while refrigerant $\mathrm{R} 600$ has a low compression ratio. The size of the compression ratio will affect the value of COP refrigeration system. Characteristics $\mathrm{COP}_{\text {LSHX }}$ are relevant to results research [3-4]. Form the value $\mathrm{COP}_{\mathrm{LSHX}}, \mathrm{R} 290 / \mathrm{R} 600 \mathrm{a}$ have closer characteristics to R22 and R600 close to R134a.

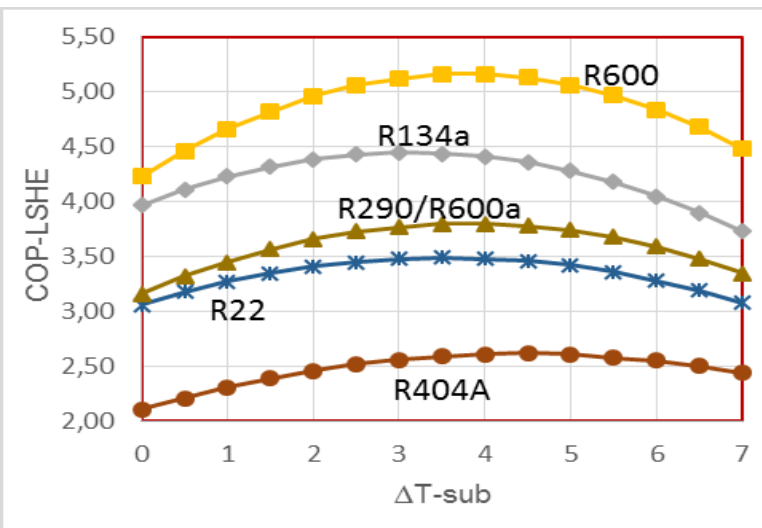

Fig. 11. Effect $\Delta \mathrm{Tsub}$ to $\mathrm{COP}_{\mathrm{LSHX}}$

The average COP index $\left(\mathrm{COP}_{\mathrm{N}}\right)$ for refrigerant $\mathrm{R} 22$, R134a, R404A, R600 and mixture refrigerant $\mathrm{R} 290 / \mathrm{R} 600 \mathrm{a}$ respectively are $1.03,1.05,1.08,1.06$ and 1.09 .

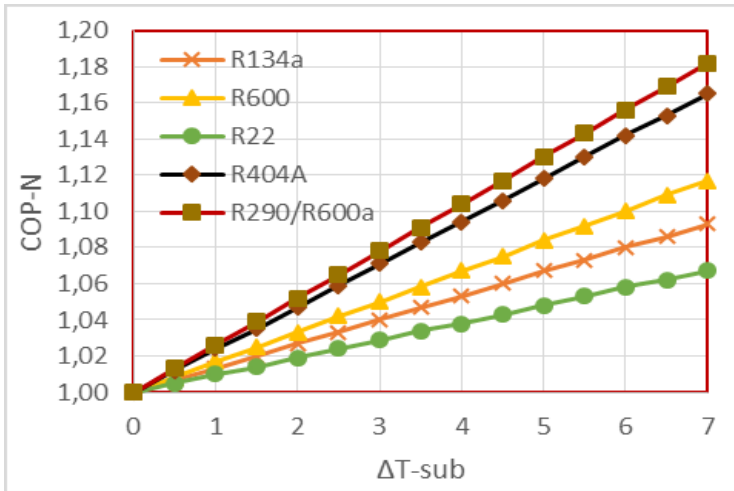

Fig.12. Effect $\Delta \mathrm{T}$ sub to $\mathrm{COP}_{\mathrm{N}}$
From Fig. 12 shows that increase degree of temperature subcooling, and then the COP index also increased. This shows that there is a significant relationship between the degree of temperature subcooling to $\mathrm{COP}_{\mathrm{N}}$ in vapor compression refrigeration system with LSHX. From the value $\mathrm{COP}_{\mathrm{N}}$, its appears that the use of LSHX is impact significantly increase $\mathrm{COP}_{\mathrm{N}}$, particularly $\mathrm{COP}_{\mathrm{N}}$ for mixture R290/R600a greater than $\mathrm{R} 404 \mathrm{~A}$ and $\mathrm{COP}_{\mathrm{N}}$ refrigerant R600 close to $\mathrm{R} 134 \mathrm{a}$. In general terms of the parameters COP, mixture refrigerant R290/R600a can be used as a substitute for refrigerant R404A and R600 can be used as substitute $\mathrm{R} 134 \mathrm{a}$ in vapor compression refrigeration system with LSHX

\section{Conclusion}

Based on the above analysis, the installation LSHX on vapor compression refrigeration system, it can be concluded that the increase degree of temperature subcooling significantly influence the effectiveness LSHX, increase refrigeration capacity, increase refrigeration capacity index, increase work compressor, increase work compressor index, $\mathrm{COP}_{\mathrm{LSHX}}$, and indexes COPN. From these indicators, that mixture refrigerant R290/R600a with the ratio of $50: 50$ can be used as a substitute for refrigerant R404A and R22, while refrigerant $\mathrm{R} 600$ can be used as a substitution of $\mathrm{R} 134 \mathrm{a}$ in vapor compression refrigeration system with LSHX.

This research is part of a research grant funding through the Higher Education Research Lecturer decentralization scheme for "Competitive Research Grant" fiscal year 2016 undur Contract No. 058.A/1/16/PKP/2016. The authors would like to thank Dr. Ir. Supriadi Legino as chairman of STT-PLN and Indrianto, ST, M.Kom. as Chairman of the Research Institute of STT-PLN

\section{References}

1. M. Nuriyadi, Sumeru, H. Nasution, Jurnal Teknologi, 76 (11), 57 (2015)

2. B.A.Qureshi, S. M. Zubair, J. Refrigeration 35, 47, (2015)

3. M.H.Yang, R.H. Yeh, J. Heat Transfer Engineering, 36 (10), 912 (2015)

4. M.H. Yang, R.H..Yeh, J., J. Heat and Mass Transfer, 87, 1 (2015).

5. B.O. Baloji, Z. Huang, J. Engineering Research, 1(1), 317 (2013)

6. B.O. Bolaji, J. Science and Technology, 34 (2), 73 (2014)

7. G. Pottker, P.S. Hrnjak, Purdue University, Purdue e-Pubs (2012), paper 1328

8. T.Ren, G. Wu, G. Ding, Y. Zheng, Y. Gao, J. Song, Purdue University, Purdue e-Pubs (2014), Paper 1407.

9. S. A. Klein, D. T. Reindl, and K. Brownell, J. Refrigeration, 23 (8), 588 (2000). 
10. L. XU, P. HRNJAK, Conference at Purdue, Purdue University, Purdue e-Pubs, July 14-17, (2014), Paper 2387

11. Prayudi, Roswati N., ARPN Journal of Engineering and Applied Sciences, 11 (2), 901 (2016)

12. Prayudi, Roswati N. and, Retno A.D., AIP Conference Proceedings, (2016) (to be published)

13. S. Wongwises, N. Chimres, J. Energy Conversion and Management, 46, 85 (2005) 